\title{
Author Correction: Unravelling the effects of mechanical physiological conditioning on cardiac adipose tissue-derived progenitor cells in vitro and in silico
}

\author{
Aida Llucià-Valldeperas ${ }^{1}$, Ramon Bragós ${ }^{2}$, Carolina Soler-Botijaa, ${ }^{1,6}$, Santiago Roura ${ }^{1,3,6}$, \\ Carolina Gálvez-Montón ${ }^{1,6}$, Cristina Prat-Vidal1,6, Isaac Perea-Gil ${ }^{1}$ \& Antoni Bayes-Genis ${ }^{1,4,5,6}$ \\ Correction to: Scientific Reports https://doi.org/10.1038/s41598-017-18799-5, published online 11 January 2018 \\ In the original version of this Article, an additional affiliation for Carolina Soler-Botija, Santiago Roura, Carolina \\ Gálvez-Montón, Cristina Prat-Vidal and Antoni Bayes-Genis was omitted. The correct affiliation is listed below: \\ CIBER Cardiovascular, Instituto de Salud Carlos III, Madrid, Spain.
}

This has now been corrected in the HTML and PDF versions of this Article, and in the accompanying Supplementary Information file.

(i) Open Access This article is licensed under a Creative Commons Attribution 4.0 International License, which permits use, sharing, adaptation, distribution and reproduction in any medium or format, as long as you give appropriate credit to the original author(s) and the source, provide a link to the Creative Commons license, and indicate if changes were made. The images or other third party material in this article are included in the article's Creative Commons license, unless indicated otherwise in a credit line to the material. If material is not included in the article's Creative Commons license and your intended use is not permitted by statutory regulation or exceeds the permitted use, you will need to obtain permission directly from the copyright holder. To view a copy of this license, visit http://creativecommons.org/licenses/by/4.0/.

(C) The Author(s) 2018

${ }^{1}$ ICREC Research Program, Health Science Research Institute Germans Trias i Pujol, Badalona, Spain. ${ }^{2}$ Electronic and Biomedical Instrumentation Group, Departament d'Enginyeria Electrònica, Universitat Politècnica de Catalunya, Barcelona, Spain. ${ }^{3}$ Center of Regenerative Medicine in Barcelona, Barcelona, Spain. ${ }^{4}$ Cardiology Service, Germans Trias i Pujol University Hospital, Badalona, Spain. ${ }^{5}$ Department of Medicine, Universitat Autònoma de Barcelona, Barcelona, Spain. ${ }^{6} \mathrm{CIBER}$ Cardiovascular, Instituto de Salud Carlos III, Madrid, Spain. Correspondence and requests for materials should be addressed to A.L.-V. (email: aida.llucia@gmail.com) or A.B.-G. (email: abayesgenis@gmail.com) 